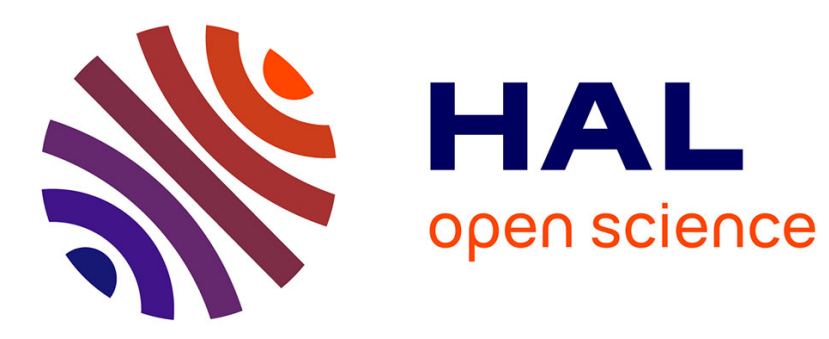

\title{
Seismic Wave Propagation in Alluvial Basins and Influence of Site-City Interaction
}

\author{
Jean-François Semblat, Marc Kham, P.Y. Bard
}

\section{To cite this version:}

Jean-François Semblat, Marc Kham, P.Y. Bard. Seismic Wave Propagation in Alluvial Basins and Influence of Site-City Interaction. Bulletin of the Seismological Society of America, 2008, 98 (6), pp.2665-2678. 10.1785/0120080093 . hal-00355601

\section{HAL Id: hal-00355601 \\ https://hal.science/hal-00355601}

Submitted on 26 Jan 2009

HAL is a multi-disciplinary open access archive for the deposit and dissemination of scientific research documents, whether they are published or not. The documents may come from teaching and research institutions in France or abroad, or from public or private research centers.
L'archive ouverte pluridisciplinaire HAL, est destinée au dépôt et à la diffusion de documents scientifiques de niveau recherche, publiés ou non, émanant des établissements d'enseignement et de recherche français ou étrangers, des laboratoires publics ou privés. 


\title{
Seismic Wave Propagation in Alluvial Basins and Influence of Site-City Interaction
}

\author{
By Jean-François Semblat*1, Marc Kham ${ }^{*}{ }^{\dagger}$, Pierre-Yves Bard** \\ * University Paris-Est, Laboratoire Central des Ponts et Chaussées \\ 58, Bd Lefebvre, 75732 Paris Cedex 15, France \\ ** LCPC/LGIT, University of Grenoble, France \\ ${ }^{\dagger}$ currently at EDF R\&D, 1, av. du Général de Gaulle, F-92141 Clamart, France
}

\begin{abstract}
The geometrical and mechanical features of alluvial deposits have a major influence on seismic wave propagation and amplification. However, for alluvial basins located in densely urbanized areas, the surface structures such as buildings could influence seismic wave propagation near the free surface. In this paper, the influence of surface structures on seismic wave propagation is analyzed numerically in the case of an actual 2D shallow basin.

At a local scale, the vibration of a surface structure can induce a seismic wavefield in the surficial soil layers. At the scale of an alluvial basin, the site-city models considered herein show that the city effect can lead to a significant seismic wavefield modification when compared to the free-field case. The coincidence between the fundamental frequencies of the soil layers and eigen frequencies of the surface structures is a key parameter to investigate site-city interaction. When comparing simplified site-city models (Kham et al., 2006) to the basin-city model, the influence of the lateral heterogeneities on the site-city interaction is found to be significant. Indeed, the seismic wavefield radiated by the city appears to be trapped within the alluvial basin and specific directivity features are found for this wavefield. The influence of site-city interaction on the free-field seismic hazard may then be significant. The effects of the site-city interaction are beneficial in some parts of the city or detrimental in other parts (esp. city boundaries). These effects strongly depend on the urban configuration (city heterogeneity, building density, etc). Finally, the full characterization of the seismic wavefield in densely urbanized areas could often raise the need for investigating site-city interaction and consider such parameters as basin and city fundamental frequencies, building density and city arrangement, as well as basin effects combined with the seismic wavefield radiated by the city.
\end{abstract}

\section{From site effects to Site-City Interaction}

The amplification of seismic waves in alluvial deposits can strengthen the incident motion and increase the consequences of earthquakes on structures and buildings. To analyze site effects, it is possible to consider modal approaches (Paolucci, 1999; Semblat et al., 2003) or directly investigate wave propagation phenomena (Frankel and Vidale; 1992, Niu and Dravinsky, 2003; Pitilakis et al., 1999; Semblat et al., 2005). Two main types of site effects can be distinguished: stratigraphic effect due to the velocity contrast between soil layers (Bard and Bouchon, 1985; Bielak et al., 1999; Chávez-García et al., 1999; Sánchez-Sesma and Luzon, 1995) and topographic effects due to specific focusing/scattering effects around crests and hills (Bouchon, 1973; Paolucci, 2002; Semblat et al., 2002). The lateral (i.e., horizontal)

\footnotetext{
${ }^{1}$ Corresponding author : semblat@lcpc.fr
} 
heterogeneities are also very important since they lead to larger amplifications which are usually known as basin effects (Bard, 1994; Bard and Bouchon, 1985; Cornou et al., 2003; Duval et al., 1998; Semblat et al., 2000, 2005). These effects are due to the propagation of surface waves from one edge of the alluvial basin to the other. They lead to larger amplifications and longer motion durations. All these analyses consider the seismic motion at the free surface, namely the "free-field" motion.

In recent years, several works and experiments focused on the potential influence of a densely built environment on the seismic response of alluvial deposits. Such an issue had never been considered seriously until the 1985 Mexico earthquake where the remarkably selective damaging of buildings, and the very strong motion amplification (in amplitude and duration), raised the question of both site effects and, more recently, city effect. Nowadays, it becomes even more critical since the rapid urbanization growth over the world has strengthened the need for safety. In order to meet this need, a scientific project was promoted by the French Ministry for Research to address the question of the so called Site-City Interaction $(S C I)$. The outcomes of this project sketch the preliminary results of the influence of a city on the seismic ground-motion. Among these works dedicated to the subject, Wirgin and others used two-dimensional numerical models to describe the diffraction pattern of surface waves under a set of buildings (Wirgin and Bard, 1996) and to assess their influence on the building motions (Groby et al., 2005). Clouteau and Aubry (2001) and Mezher (2004) performed 3D computations based on boundary element models to characterize the SCI in the case of Nice (France) and Mexico City. Kham et al. (2006) considered simplified 2D boundary elements models (periodic and homogeneous cities over a constant-depth layer) for a parametric analysis of the influence of the city configuration on the ground motion. On the other hand, several authors attempted to give a semi-analytical description of the SCI. For example, Guéguen et al. (2000) described the global city effect by adding the single contributions of each building represented by a simple oscillator, while the model proposed by Boutin et al. (2004) accounts for the multiple interactions between buildings through homogenization methods. Finally, some experimental studies were also conducted to assess the SCI: Jennings (1970) first discussed the influence of building vibration in terms of radiated wavefield; the Volvi experiment, performed by Guéguen et al. (2000), recorded the wavefield radiated by a vibrating structure (reduced scale building); and experiments in Mexico City by Chávez-García and Cárdenas-Soto (2002) highlighted the influence of two tall buildings by $\mathrm{H} / \mathrm{V}$ spectral ratios.

As summarized by Bard et al. (2005), all these works tend to indicate that the SCI may result in significant effects on the ground motion:

- The SCI is strengthened when eigen frequencies of the soil and the buildings coincide,

- The SCI mostly tends to decrease the surface ground-motion,

- An increase of the city density reinforces the ground-motion modification,

- Multiple interactions may increase the signal duration,

- The wavefield radiated by the city increases the ground motion outside the city and near its boundaries,

- The waves diffracted by the buildings may strongly decrease the ground-motion coherency. 
In all previous theoretical or numerical models considered to address the subject, a onedimensional soil profile was always considered. This is legitimate since for such a new issue the first attempt is to reach a comprehension of the basic phenomena. However, the seismic response of a 2D basin may significantly differ from that of a 1D layer (e.g., trapped surface waves). One thus may wonder: what are the main phenomena characterizing SCI in alluvial basins and how large is their influence on free-field site effects? In the present study, we attempt to address this question for a 2D basin. Our goal is definitely not to solve the whole problem but to assess the reliability of the conclusions of the 1D layer case for 2D alluvial basins and provide some preliminary results to guide possible further investigations.

\section{Site-city models involving an alluvial basin}

\section{Alluvial basin considered and free-field amplification}

A 2D shallow geological structure located in the centre of the city of Nice (French Riviera) is considered. As shown in Figure 1 (middle), the site model is represented by a $2100 \mathrm{~m}$ wide $60 \mathrm{~m}$ deep basin. This model was proposed by Semblat et al. (2000) to model site amplification in the city of Nice. The deepest point of the basin is located at around $500 \mathrm{~m}$ from the western edge of the basin. The material properties of the basin and the bedrock are given in Figure 2. Both the basin and the bedrock are homogeneous, isotropic and viscoelastic media. Since we aim to analyze the mechanisms of the site-city interaction and not to produce an earthquake scenario, we shall skip unnecessary details and discussion about the representativity of the basin; the key point is the respective dynamic features of the basin on one hand and the buildings on the other (Kham et al., 2006).

\section{Figure 1}

Free-field site effects have been previously studied in details for this basin using the Boundary Element Method in the frequency domain (Semblat et al., 2000). As shown in Figure 1 (bottom), the seismic wave amplification is strongly underestimated by 1D analysis (by a factor 2 or 3), whereas 2D computations lead to spectral amplifications very close to the experimental site/reference spectral ratios. The fundamental frequency of the basin is $\mathrm{f}_{0} \mathrm{~S}=0.8 \mathrm{~Hz}$. It is controlled mainly by the geometrical/dynamic properties of the deepest part (Semblat et al. 2000, 2003). In the eastern shallower part, the frequency corresponding to the largest amplification is $\mathrm{f}_{1}^{\mathrm{S}}=2.0 \mathrm{~Hz}$. For this shallow basin, the influence of $2 \mathrm{D}$ effects (e.g., surface-wave generation) appears to be strong (Fig.1, top). It is thus an interesting case for a detailed analysis of site-city interaction, taking into account the influence of surface structures.

\section{Site-city models considered}

As depicted in Figure 2, four city models are considered and placed at the centre of the basin. Two regular cities involve a periodic arrangement of identical buildings. An irregular city randomly combines two building types, and a so-called realistic city covers the whole basin surface with an arbitrary alternation of two building types. These city models are described as follows:

- Firstly, a regular city involving identical and equally spaced buildings along a distance L at the centre of the basin (Fig.2). Two types of buildings are considered:

1) $40 \times 15 \mathrm{~m}$ buildings with shear resonant frequency $\mathrm{f}^{\mathrm{B}}=1 \mathrm{~Hz}$ (type B1S) close to the basin fundamental frequency $\mathrm{f}_{0} \mathrm{~s}$

2) $30 \times 10 \mathrm{~m}$ buildings with shear resonant frequency $\mathrm{f}^{\mathrm{B}}=2 \mathrm{~Hz}$ (type $\mathrm{B} 2 \mathrm{~S}$ ) close to the 
frequency of maximum amplification of the shallower part $\mathrm{f}_{1} \mathrm{~S}$.

The soil-structure interaction being taken into account for each single building (building over a half-space with properties similar to that of the alluvial deposit), the buildings' properties are tuned in order to obtain these frequency values.

- Secondly, an irregular city made of an arbitrary alternation of six B1S ( $\left.\mathrm{f}^{\mathrm{B}}=1 \mathrm{~Hz}\right)$ and seven $\mathrm{B} 2 \mathrm{~S}\left(\mathrm{f}^{\mathrm{B}}=2 \mathrm{~Hz}\right)$ buildings along a distance $\mathrm{L}=500 \mathrm{~m}$ and centred in the basin (Fig.2).

- Thirdly, a so called "realistic city" made of an alternation of B1S and B2S buildings arbitrarily distributed along the whole basin, which is assumed to be more representative of the densely built environment of an actual city (especially Nice City for this alluvial basin).

Figure 2

We note that the two first city models were used by Kham et al. (2006) for the simplified analysis of the site-city interaction over a 1D soil profile. Reference will be made to this previous article for comparisons.

Both the site and the city are modeled by a classical direct boundary element formulation (Dangla, 1988; Dangla et al., 2005; Semblat et al., 2000) using the FEM/BEM code CESARLCPC (see Data and Resources section and (Humbert et al., 2005)). The formulation and the computations are made in the frequency domain (Dangla et al., 2005). The solutions are synthetized afterwards in the time domain. They are compared for the different cities and various excitations. New developments of the method are currently in progress in the framework of fast multipole formulations (Chaillat et al., 2008).

For the site-city models, the boundary conditions applied at the interface between each building and the soil are continuity of displacements and tractions. The bedrock, the basin and the buildings are assumed to be homogeneous visco-elastic media following the standard solid constitutive law (Semblat et al., 2000).

Their mechanical properties are given in Figure 2: the properties of the realistic basin correspond to its average actual characteristics. The influence of the impedance ratio was already considered in previous works for free-field amplification (Semblat et al., 2000) as well as for site-city interaction using simplified soil models (Kham al al., 2006). The influence of damping variations was not considered in this work since the influence of impedance contrast is expected to be much larger. The influence of energy dissipation should be taken into account for strong events, i.e., larger attenuation (Delépine et al., 2007). Both models for the basin and the city are restrained to two dimensions to make the parametric analysis of site-city interaction easier.

The site-city model is submitted to an upcoming plane SH wave with vertical incidence. In time domain, the excitation is a second order Ricker waveform with amplitude $U_{0}$ and central frequency $\mathrm{f}^{\mathrm{R}}$, of the following form:

$$
\mathrm{R}(\mathrm{t})=\mathrm{U}_{0}(\mathrm{a}-1) \exp (-\mathrm{a})
$$

where $a=\pi^{2}\left(\left(t-t_{S}\right) / t_{P}\right)^{2}$, and $t_{S}$ and $t_{P}$ are the peak position and the characteristic period of the signal respectively. The city response is computed over a total duration of $20 \mathrm{~s}$.

Computations were also performed for a real earthquake (considered as an upgoing plane $\mathrm{SH}$ wave), corresponding to the magnitude $\mathrm{M}_{\mathrm{w}}=4.6$ that struck the city of Nice in February 
2001 (Fig.1, top), located 30km away in the Mediterranean Sea (see Data and Resources section).

\section{Site-city interaction for regular cities}

For the regular cities, four building densities, $\theta$, are considered: $\theta=0.23,0.37,0.57$ and 0.74 for the B1S city ; $\theta=0.2,0.32,0.5$ and 0.66 for the B2S city. Density is defined by $\theta=\mathrm{NB} / \mathrm{L}$, where $\mathrm{N}$ is the number of buildings and $\mathrm{B}$ their base width. Four values of $\mathrm{N}$ were considered - 10, 16, 25 and 33, and L was set to $665 \mathrm{~m}$ for the B1S city and L=500m for the B2S city in order to establish the above building densities.

\section{Influence of the city on the seismic ground-motion}

In Figures 3 and 4, the ground motion is displayed at 6 points along the city. Point \#1 is located at $295 \mathrm{~m}$ from the western basin edge and the following points are located at $250 \mathrm{~m}$ intervals. In columns 1 and 3, the solutions obtained for the B1S city and the B2S city ( $=33)$ are compared to the free-field in terms of amplification (Fig. 3), i.e., $u(f) / \mathrm{U}_{0}$ spectra (referred to as transfer functions from now on), and in terms of normalized displacement (Fig. 4), i.e., $\mathrm{u}(\mathrm{t}) / \mathrm{U}_{0}$ (Ricker wavelet of central frequency $\mathrm{f}^{\mathrm{R}}=0.8 \mathrm{~Hz}$ ).

In the frequency domain (Fig.3), it clearly appears that the B1S city strongly affects the fundamental peak of the site response. This is especially the case for points 3, 4 and 5 located inside the B1S city: the resonant peak is significantly decreased and split into two lower peaks, as already noted by Boutin and Roussillon (2004) or Kham et al. (2006). By comparison, the regular B2S city influence (dotted line) appears rather slight. This result highlights the fact that the city effect becomes effective mainly if the resonant frequency of the soil is close to that of the buildings $\left(\mathrm{f}^{\mathrm{B} 1 \mathrm{~S}}=1 \mathrm{~Hz}\right)$. It also shows that the dynamic interaction between the city and the soil is significant, since, if this was not the case, both cities should give comparable results. Such considerations were already derived from the analysis of the 1D layer case. In the case of the alluvial basin, one would expect additional lateral effects due to depth variation.

While such a variation appears in the spectra (Fig.3) from one point to another, the influence of the city on the lateral effects is more visible in the time histories (Fig.4, $1^{\text {st }}$ and $3^{\text {rd }}$ columns). Submitted to a Ricker wavelet of central frequency $\mathrm{f}^{\mathrm{R}}=0.8 \mathrm{~Hz}$, a surface wave indeed propagates along the western part of the basin (points 1 to 4, between 7 and 15s). The B1S city nonetheless tends to lower the amplitude of the direct wave especially inside the city. By comparison, the influence of the B2S city along the basin surface (dotted line) seems less in terms of amplitude. This influence is probably due to a shift of the responses to a lower frequency. This shift may be related to the additional mass provided by the buildings and so is relevant to the so called inertial effect of the city. On the contrary, for the B1S city, the sitecity interaction is much more effective since the respective frequencies of the buildings and the basin are rather close to each other.

Figure 3

Figure 4

\section{Influence on the ground-motion duration}

These differences are obvious when considering the signal durations (Fig.5). Although there are many different definitions of signal duration (Bommer and Martinez-Pereira, 1999), 
we use here the 5-95\% significant duration proposed by Trifunac and Brady (1975). For the B1S city with an input signal of $\mathrm{f}^{\mathrm{R}}=0.8 \mathrm{~Hz}$ (top left), the signal duration is strongly modified by the city. In the left part of the basin, it is lower for the largest city densities than in the freefield case ; at the center of the city, it is larger for all building densities than in the free-field case. For the B2S city with an input signal at $\mathrm{f}^{\mathrm{R}}=0.8 \mathrm{~Hz}$ (Fig. 5 , top right), the motion duration increases with the building density but the difference is much smaller than for the B1S city. This increase is probably due to a modification of surface-wave propagation in the basin because of the B2S city. At 2Hz (Fig. 5, bottom), the signal duration for B1S and B2S cities is very close to that of the free-field.

Figure 5

\section{Scattered wavefield for the regular cities}

The global effect of the regular cities on the ground motion appears more clearly in Figures 6 and 7 where the wavefield is displayed along the basin free surface for the B1S and the B2S cities respectively (Ricker wavelet of central frequency $\mathrm{f}^{\mathrm{R}}=0.8 \mathrm{~Hz}$ ). The ground motion computed in both cases is compared to the free-field (Fig. 6, top). The ground-motion reduction induced by the cities obviously appears in both cases. However, the reduction is stronger for the B1S city (Fig. 6, middle) than for the B2S (Fig. 7, top), especially inside the city. According to previous considerations, this point is due to the dynamic interaction between the soil and the B1S buildings array which both resonate under $\mathrm{f}^{\mathrm{R}}=0.8 \mathrm{~Hz}$ because the frequency of the basin $\mathrm{f}_{0}{ }^{\mathrm{S}}(=0.8 \mathrm{~Hz})$ is close to that of the buildings $\mathrm{f}^{\mathrm{B}}(=1 \mathrm{~Hz})$. For the $\mathrm{B} 2 \mathrm{~S}$ city, the fundamental period of the surface wavefield slightly increases. As already mentioned, this may be due to the additional mass of the B2S buildings which decreases the fundamental frequency of the soil-building system. In order to assess the ground response modification due to the cities, we compute the induced ground-motion perturbations $\mathrm{u}^{\mathrm{P}}=\mathrm{u}^{\mathrm{T}}-$ $\mathrm{u}^{\mathrm{FF}}$ as the difference between the total ground motion $\mathrm{u}^{\mathrm{T}}$ (with the city) and the free-field motion $u^{\mathrm{FF}}$. These results are then displayed at the bottom of Figures 6 and 7 for B1S and B2S city respectively. These perturbations appear as a scattered wavefield, radiated by the city. The diffracted waves originate from within the city and mainly propagate westward in the basin. Such a feature is obviously related to the directivity of surface waves generated in the deepest part of the basin at an excitation frequency close to its fundamental frequency. However, these scattered waves play a beneficial role since they tend to interfere with the original wavefield and reduce the ground motion inside the city.

Figure 6

Figure 7

\section{Ground shaking energy induced by the site-city interaction}

In order to give a global assessment of the site-city interaction, we consider the groundmotion energy along the basin induced by the SCI. We define the ground energy as follows:

$$
E(x)=\frac{1}{T} \int_{0}^{T}\left[\frac{d u}{d t}\right]^{2}(x, t) d t
$$

where $\mathrm{T}$ stands for the signal duration in the computation (i.e., 20s).

Figure 8 shows the actual to free-field energy variation $\mathrm{E} / \mathrm{E}^{\mathrm{FF}}$ for B1S (left column) and B2S (right column) cities along the basin for different urban densities and various excitations. 
Also shown is the ratio between the energy of the ground-motion perturbations $\mathrm{u}^{\mathrm{P}}$ and the free-field energy. This ratio, denoted $\mathrm{E}^{\mathrm{P}} / \mathrm{E}^{\mathrm{FF}}$, is represented in the same way (thin lines at the bottom of each graph).

For different excitation frequencies, the energy distribution is obviously not similar either for B1S city or B2S city. Once again, this indicates that the coincidence between the buildings vibratory features, the fundamental soil frequency and the predominant signal frequency controls the strength of dynamic site-city interaction. Such interaction is strengthened when resonant frequencies of the soil and the buildings are close (for example the B1S city above the deepest western part of the basin) and clearly induces a reduction of the ground-motion energy inside the city (B1S city under $\mathrm{f}^{\mathrm{R}}=0.8 \mathrm{~Hz}$, top-left, and $\mathrm{B} 2 \mathrm{~S}$ city under $\mathrm{f}^{\mathrm{R}}=2 \mathrm{~Hz}$, middle right). In favourable cases (B1S city), such a reduction may be significant, reaching $70 \%$ of the free-field energy. Increasing the density (i.e., the cumulative mass of the city, $\mathrm{L}$ being constant) reinforces the energy decrease when it occurs. As mentioned in previous analyses with a 1D constant layer (Kham et al., 2006), the density increase is equivalent in this case to inertial effect strengthening. However, this mass influence of the city is active when site-city resonance occurs. The ground energy decrease is then attributed indistinctively to both dynamic interaction (structural effect of the city and multiple soil-building interaction) and inertial effect (no structural effect, global influence of the city). But when site-city resonance does not occur, inertial effect solely acts and may lead to either ground energy reduction (B1S, middle-left) or increase (B2S, top-right) inside the city.

This last point was not predicted by the 1D layer analysis and may specifically characterize $2 \mathrm{D}$ effects in the basin. In the B2S city case under $\mathrm{f}^{\mathrm{R}}=0.8 \mathrm{~Hz}$ for example (top-right), since the site-city dynamic resonance is not reached, the building responses within the city become quite heterogeneous, and since the total mass of the buildings is less than for the B1S city, the inertial effect seems to be insufficient to induce a ground energy reduction. Nevertheless these factors only partly explain the differences between B1S and B2S cities, since they may be submitted to different excitation patterns (changes in main amplification area, differences in surface-wave patterns) because of the $2 \mathrm{D}$ effects in the basin. This point is obviously the most difficult issue to address for realistic 2D basins, and we will surely not be able to definitely close the subject herein. One should also notice the sharp variations in ground energy (let us

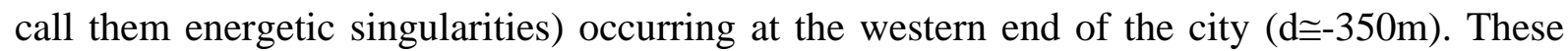
singularities may give rise to energy peaks up to $60 \%$ over the free-field energy. This point may be important since lighter buildings located in this area may suffer strong ground motion and sharp lateral ground-motion variations. Such singularities may be explained by the additional model horizontal heterogeneity at the free-field/city interface. The westward radiated perturbation wavefield is probably responsible for such peaks.

In Figure 8, the perturbations to free-field energy ratio $\mathrm{E}^{\mathrm{P}} / \mathrm{E}^{\mathrm{FF}}$ normally grows with density and is larger inside the city, where the diffraction occurs, than outside. At the bottom of Figure 8, the ground energy distribution under the Feb.2001 earthquake is displayed for B1S and B2S city. This earthquake was recorded by the French accelerometric network (see Data and Resources section) and its time history is displayed in Figure 1 (top). Since its dominant frequency is below $1 \mathrm{~Hz}$, the energy reduction for B1S city and slight increase for B2S city are quite consistent with previous results. Such a consideration may allow ground energy assessment for real earthquakes from simpler excitation analysis (by a single wavelet).

Figure 8 


\section{Site-city interaction for an irregular city}

We now consider the case of the irregular city presented in Figure 2 (top). This city is $500 \mathrm{~m}$ wide and centered in the basin. The site-city model is submitted to a plane vertical SH wave. In time domain, the excitation remains a second order Ricker wavelet with central frequency $\mathrm{f}^{\mathrm{R}}$. Comparisons to the Feb.2001 earthquake are also considered.

\section{Influence on the ground motion}

The irregular city involves both B1S and B2S buildings, and it appears from Figures 3 and 4 (curves with dotted lines in columns 2 and 4) that the computed ground motions are between the solutions for B1S and B2S regular cities. The fundamental peak around $1 \mathrm{~Hz}$ is reduced at points 3 and 4 inside the city but is not fully split into two separate peaks as for the B1S regular city. As shown in Figure 4 ( $2^{\text {nd }}$ and $4^{\text {th }}$ columns), the same consideration also stands for time histories under a Ricker wavelet $\left(\mathrm{f}^{\mathrm{R}}=0.8 \mathrm{~Hz}\right)$ where the amplitude decrease is larger than for the B2S regular city, especially for surface waves, but lower than for the B1S regular city.

A global insight into the ground response is possible through Figure 9 where the total ground motion and ground-motion perturbations under a $0.8 \mathrm{~Hz}$ Ricker wavelet are displayed along the basin. When compared to the free-field (Fig.6, top), the ground-motion reduction appears clearly inside the city. Nonetheless, the perturbations also clearly show that the scattered wavefield mainly occurs in the western part of the irregular city, where the local density (namely of B1S buildings) is larger. It is also clear that the response of the irregular city becomes irregular and inhomogeneous, as was already pointed out in the previous analysis with the $1 \mathrm{D}$ layer.

Figure 9

\section{Ground shaking energy along the basin}

Similarly to the regular city case, the ground motion to free-field energy ratio $\mathrm{E} / \mathrm{E}^{\mathrm{FF}}$ is now displayed in Figure 10 under various excitations, i.e., Ricker wavelets of central frequencies $\mathrm{f}^{\mathrm{R}}=0.8 \mathrm{~Hz}$ and $2 \mathrm{~Hz}$, as well as the Nice 2001 earthquake. The perturbations energy ratio with respect to free-field, $\mathrm{E}^{\mathrm{P}} / \mathrm{E}^{\mathrm{FF}}$, is also plotted (bottom curves).

The ground energy decreases in the western part of the city where the density is larger, as previously noted for the ground response analysis. This energy reduction is stronger for $\mathrm{f}^{\mathrm{R}}=0.8 \mathrm{~Hz}$ and can reach $60 \%$ of the free-field energy, obviously because B1S buildings are involved in the site-city interaction. Such a value is comparable to the regular city case (Fig.8) but concerns the very local area where several B1S buildings are actually very close to each other (near zero abscissa). On the other hand, the ground energy is appreciably larger in the eastern part of the city, and also more variable, especially for $\mathrm{f}^{\mathrm{R}}=0.8 \mathrm{~Hz}$ where $\mathrm{E} / \mathrm{E}^{\mathrm{FF}}$ may locally exceed 1 . All these observations mainly show that the ground energy variation may be very irregular in an irregular city and strongly depends on the city configuration and buildings types. Therefore under similar 2D basin effects, the irregular city may strengthen the ground incoherency whereas a regular city may smooth it. The difference between the two halves of the city is obvious in the perturbations energy which is clearly larger in the western part (left) than in the eastern (right). Sharp energetic singularities are still present next to the western edge of the city, as in the former regular city case and probably for similar reasons (horizontal heterogeneities at the free-field/city interface). Finally, the ground energy variation for the 
actual 2001 earthquake again gives results comparable to $\mathrm{f}^{\mathrm{R}}=0.8 \mathrm{~Hz}$, which is reasonable since the earthquake frequency bandwidth is essentially [0 - 1] Hertz.

Figure 10

\section{Site-city interaction for a "realistic city"}

Let us now consider an arbitrary alternation of 48 B1S buildings and 46 B2S buildings all along the basin surface as shown in Figure 11. Such a city will be referred to as a "realistic city" in the sense that it is close to the real configuration of Nice City and involves, for the sake of comparison, the same types of buildings as in the previous sections. However, this does not mean that the site-city model will actually give the real behaviour of the city under an earthquake, since the building locations are arbitrary. In that sense, we are always considering a theoretical analysis and do not attempt to create an earthquake scenario. Nevertheless, such a city model is of great interest since it sketches what may occur in the critical case of a realistic situation where the buildings features match the basin features within a large irregular urban arrangement.

The site-city model is submitted to various upcoming SH plane wave excitations, i.e., Ricker wavelets of central frequencies $\mathrm{f}^{\mathrm{R}}=0.8 \mathrm{~Hz}$ and $2 \mathrm{~Hz}$, and the Feb.2001 earthquake.

\section{Figure 11}

\section{Analysis of the ground motion along the basin}

As in the previous sections, the ground motion is firstly compared to the free-field for 6 points along the basin in terms of spectral amplitude and time histories. The traces are displayed by thick lines in columns 2 and 4 of Figures 3 and 4.

The spectral amplitude reduction is obvious not only for the principal peak around $1 \mathrm{~Hz}$ but also at $2 \mathrm{~Hz}$. Furthermore, the city also seems to attenuate the sharp ridges in the free-field spectra known to be due to lateral effects, and especially lateral surface waves (points 4, 5 and $6 ; 2^{\text {nd }}$ and $4^{\text {th }}$ columns). Therefore, from the amplitude spectra, we can expect the realistic city to strongly influence the surface-wave propagation patterns along the basin. This point is confirmed by time histories (Fig.4) where the attenuation of the main and secondary free-field oscillations is obvious. However, such attenuation does not look so spectacular when compared to the B1S regular city. On the contrary, the signal duration seems to be slightly longer than in the B1S city in some cases (point 3 for example).

Better insight is obtained from Figure 12, where the ground motion and perturbations are displayed along the basin for a Ricker wavelet $\left(\mathrm{f}^{\mathrm{R}}=0.8 \mathrm{~Hz}\right)$. The expected reduction of the surface-wave generation is very clear in the western part of the basin, but more in terms of amplitude rather than in terms of duration. Since the density of B1S buildings is lower than in the B1S regular city, wave attenuation in the realistic city is smaller than in the regular city (Fig.7). However, the B1S building arrangement covers the whole basin area and tends to behave uniformly, like a thin elastic layer, opposing any kind of lateral variation. The perturbation wavefield in the deepest part of the basin shows a kind of double, westward and eastward, directivity effect (due to the contribution of the building network). This directivity effect is very different from the regular city case (Fig. 6).

Figure 12

\section{Analysis of the ground energy along the basin}


We now focus on the ground motion to free-field energy ratio along the basin for several excitations, i.e., Ricker wavelets of central frequencies $\mathrm{f}^{\mathrm{R}}=0.8 \mathrm{~Hz}$ and $2 \mathrm{~Hz}$, and the Feb.2001 earthquake. Both the ground-motion and perturbations energies are displayed in Figure 13.

The ground-motion energy decreases by $60 \%$ in the western part for $\mathrm{f}^{\mathrm{R}}=0.8 \mathrm{~Hz}$ and both in the eastern and western parts for $\mathrm{f}^{\mathrm{R}}=2 \mathrm{~Hz}$. In the former case, since $\mathrm{f}_{0} \mathrm{~S}=0.8 \mathrm{~Hz} \cong \mathrm{f}^{\mathrm{B} 1 \mathrm{~S}}$, we believe the decrease is due to the site-city interaction activated by the B1S buildings. In the latter case, since the basin thickness is about $\mathrm{H}=30 \mathrm{~m}$ in the east (ie $\mathrm{f}_{1}{ }^{\mathrm{S}} \cong 2 \mathrm{~Hz}$ ), the site-city interaction may also be activated by B2S buildings. The site-city interaction activation in each case is perhaps more obvious in the perturbation energy along the basin, which is clearly increased in one or the other side of the basin according to excitation frequency $\mathrm{f}^{\mathrm{R}}$. What is remarkable is that the ground energy is increased by $60 \%$ in the east for $\mathrm{f}^{\mathrm{R}}=0.8 \mathrm{~Hz}$, while it is decreased in the west for $\mathrm{f}^{\mathrm{R}}=2 \mathrm{~Hz}$ as aforementioned. Consistently with previous considerations, an explanation is that we face energetic singularities in the first case and city's inertial effect in the second. But how are the energetic singularities explainable since there is no a priori surface discontinuity along the random city? One possible answer is that there is a structural discontinuity between the resonating and the non-resonating sections of the city. If true, such an answer justifies the distinction between site-city dynamic interaction and simple inertial effect. Another question is then: why is no energetic singularity observed in the west for $\mathrm{f}^{\mathrm{R}}=2 \mathrm{~Hz}$ ? In this case, one may assume that the inertial effect in the western part is stronger and overwhelms the SCI. Presently, it is difficult to give clear analyses and predictions since we believe that one case or another depends on many parameters, such as the site amplification patterns along the basin, the excitation frequency band, etc. This last point is supported by the fact that the ground energy repartition for Feb.2001 earthquake significantly differs from the Ricker response at $\mathrm{f}^{\mathrm{R}}=0.8 \mathrm{~Hz}$. All these considerations show that when a realistic site-city configuration is considered (random city over a 2D basin profile), the sitecity interaction effect is certainly not easy to assess or predict, since many parameters may be involved.

In order to assess the site-city interaction effect over a 1D layer, a practical formula was proposed by Guéguen et al. (2000). It gives an approximation of the ratio of the kinematic energy radiated by the city $E_{B}$ to the soil kinematic energy $E_{S}$, as follows:

$$
\frac{E_{B}}{E_{S}} \cong \sum_{i=1}^{N}\left[\frac{S_{B i}}{S_{S}} \cdot \frac{H_{B i}}{H_{S}} \cdot\left(\frac{f_{S}}{f_{B i}}\right)^{2}\right]
$$

where $N$ is the total number of buildings, $S_{B i}$ is the surface occupied by building $i, S_{S}$ that occupied by the soil, $H_{B i}$ and $H_{S}$ are the height of building $i$ and that of the soil, respectively ; $f_{B i}$ and $f_{S}$ the fundamental frequencies of building $i$ (interacting with the soil) and that of the soil, respectively.

Averaging the basin thickness to $\mathrm{H}=50 \mathrm{~m}$ ( $\mathrm{H} \cong 60 \mathrm{~m}$ in the west and $\mathrm{H} \cong 40 \mathrm{~m}$ in the east), a fundamental frequency of $f_{S}=1 \mathrm{~Hz}$ is obtained for the equivalent layer. In the case of our realistic city model, it leads to $E_{B} / E_{S} \cong 0.25$, which is close to the value $\left(E_{B} / E_{S} \cong 0.2\right)$ computed by Guéguen et al. (2000) for Nice South Railway Station. While these values are comparable, we obtained with our computational model $\mathrm{E}^{\mathrm{P}} / \mathrm{E}^{\mathrm{FF}} \cong 0.6$ (Fig.13). Such a difference may be due not only to the 2D basin effect which is actually accounted for herein, but also to the inertial effect related to the accumulated mass of the buildings (Guéguen's formula sums up the energy radiated from each building separately). 


\section{Ground motions within and near the city for actual earthquakes}

In order to link energy variation to ground motion, we finally compare surface displacement time histories at three locations along the basin where energy values are respectively very high and very low (Fig.14, top right). Such a comparison is given for the various city models and the free-field under the Feb.2001 earthquake. It seems obvious that energy increase or reduction are linked to signal amplification or deamplification. This is particularly clear at point 2 where the regular B1S city actually amplifies the free-field motion and at point 3 where deamplification is significant for the regular B1S, irregular and realistic cities. Such results support the idea that the city may strongly influence the ground response and could significantly modify the free-field seismic hazard.

Figure 13

Figure 14

\section{Conclusions}

A two-dimensional basin profile induces strong amplification/ deamplification for both the amplitude and the duration of the seismic response. It also leads to sharp lateral variations of the ground motion mainly due to surface-wave propagation. Despite such conditions (different from the 1D soil layer case previously proposed by Kham et al. (2006)), site-city interaction may still occur when the buildings' eigenfrequencies match the soil fundamental frequency $\left(\mathrm{f}^{\mathrm{S}}=\mathrm{f}^{\mathrm{B}}\right)$. The amplitude of the seismic ground-motion is then strongly reduced: the main oscillations, and especially the surface waves, are significantly decreased. The motion duration is also modified since the signals may be lengthened or shortened depending on both the frequency coincidence and the building density. When the site-city interaction is supposed to be insignificant $\left(\mathrm{f}^{\mathrm{S}} \neq \mathrm{f}^{\mathrm{B}}\right)$, the ground motion may still be reduced by the city's inertial effect, provided the city is dense enough or the buildings are massive enough. When $\mathrm{f}^{\mathrm{S}}=\mathrm{f}^{\mathrm{B}}$, the inertial effect may combine with the site-city interaction, which is consequently reinforced, resulting in strong ground motion decrease by up to $60 \%$ of the free-field. Sharp energetic singularities can also be observed on the edges of the building network and give rise to energetic peaks up to $160 \%$ of the free-field energy. In the case of a random city, these peaks may also be found inside the city, at junctions of building groups of contrasting dynamic features. Outside the city, a significant wavefield radiated from the buildings is observed with specific directivity features strongly influenced by the basin effects.

Finally, in the case of a two-dimensional basin, it is concluded that the effects of site-city interaction are difficult to fully determine, since they depend on many parameters such as the buildings' mechanical features, their arrangement inside the city, their exact location with respect to the basin shape, the basin geometry, the excitation frequency, etc., and other important factors not yet addressed such as inclined incident waves, 3D configurations (Mezher, 2004) or soil non-linearity (Delépine et al., 2007). Site-city interaction could nevertheless be a critical issue since it may significantly modify the free-field seismic wavefield predicted by usual methods. However, it is difficult to assess SCI for actual sites through experimental methods. Several recent results are probably encouraging for future work, namely: dense array analysis (Cornou et al., 2003), propagation in heterogeneous media (Campillo, 2006; Chammas et al., 2003; Lombaert et al., 2004), as well as reduced scale experimental analyses with and without the city (Chazelas et al., 2001). 


\section{Data and Resources}

Numerical simulations performed in this work used the FEM/BEM software CESARLCPC (information available at www.cesar-lcpc.com). Seismograms used in this study come from the French Accelerometric Network/Réseau Accélérométrique Permanent ('RAP'). Data can be obtained at www-rap.obs.ujf-grenoble.fr.

\section{Acknowledgements}

The authors would like to acknowledge the team of the French national project ACI CATNAT on "Seismic hazard in urban areas" in the framework of which this work was made possible. They would also like to thank Philippe Guéguen for his pioneering work on the SCI, which was the starting point of our numerical investigations. The authors are finally grateful to the reviewers of this paper, and to the Associate Editor as well, for their valuable and detailed comments on the preliminary version of the text.

\section{References}

Bard, P.Y. and Bouchon, M. (1985). The two dimensional resonance of sediment filled valleys, Bull. Seism. Soc. Am. 75, 519-541.

Bard, P.Y. (1994). Effects of surface geology on ground motion : recent results and remaining issues, 10th European Conf. on Earthquake Eng., Vienna, 1, 305-323.

Bard, P.-Y., J.-L. Chazelas, P. Guéguen, M. Kham, J.-F. Semblat, (2005). Assessing and managing earthquake risk - Chap.5: Site-city interaction, C.S.Oliveira, A.Roca and X. Goula Eds, Springer, $530 \mathrm{p}$.

Bielak J., Xu J., Ghattas O. (1999). Earthquake ground motion and structural response in alluvial valleys, J. Geotech. Geoenviron. Eng. 125, 413-423.

Bommer, J.J., Martinez-Pereira, A. (1999). The effective duration of earthquake strong motion, J. of Earthquake Eng. 3, 127-172.

Bonnet, M. (1999). Boundary integral equation methods for solids and fluids, Wiley, Chichester, UK.

Bouchon, M. (1973). Effects of topography on surface motion, Bull. Seism. Soc. Am. 63, 615-622.

Boutin, C. and Roussillon, P. (2004). Assessment of the urbanization effect on seismic response, Bull. Seism. Soc. Am. 94, no.1, 251-268.

Campillo, M. (2006). Phase and correlation in 'random' seismic fields and the reconstruction of the Green function, Pure appl. geophys. 163, 475-502.

Chaillat S., Bonnet M., Semblat J-F (2008), A multi-level fast multipole BEM for 3-D elastodynamics in the frequency domain, Computer Methods in Applied Mechanics and Eng., doi:10.1016/j.cma.2008.04.024, to appear.

Chammas R., O.Abraham, P.Cote, H.Pedersen, J.F.Semblat (2003). Characterization of heterogeneous soils using surface waves : homogenization and numerical modeling, Int. Jal Geomechanics, 3, no.1, 55-63.

Chávez-García, F.J., Stephenson, W.R., Rodríguez, M. (1999). Lateral propagation effects observed at Parkway, New Zealand. A case history to compare 1D vs 2D effects, Bull. Seism. Soc. Am. 89, 718-732.

Chávez-García F.J. and Cárdenas-Soto M. (2002). The contribution of the built environment to the free-field ground motion in Mexico city, Soil Dyn. Earthq. Eng. 22, 773-780.

Chazelas J.L., Abraham O., Semblat J.F. (2001), Identification of different seismic waves generated by foundation vibration: centrifuge experiments, time-frequency analysis and numerical 
investigations, 4th Int. Conf. on Recent Advances in Geotechnical Earthquake Eng. and Soil Dynamics, San Diego.

Clouteau, D. and Aubry, D. (2001), Modifications of the ground motion in dense urban areas, Journal of Computational Acoustics, 9, 1659-1675.

Cornou, C., Bard, P.Y., Dietrich, M. (2003). Contribution of dense array analysis to the identification and quantification of basin-edge-induced waves, Bull. Seism. Soc. Am. 93, no.6, 2604-2623.

Dangla, P. (1988), A plane strain soil-structure interaction model, Earthquake Eng. and Structural Dynamics, 16, 1115-1128.

Dangla P., Semblat J.F., Xiao H.H., Delépine N. (2005). A simple and efficient regularization method for 3D BEM: application to frequency-domain elastodynamics, Bull. Seism. Soc. Am. 95, n 5 , 1916-1927.

Delépine N., Bonnet G., Semblat J-F, Lenti L. (2007). A simplified non linear model to analyze site effects in alluvial deposits, 4th Int. Conf. on Earthquake Geotechnical Eng., Thessaloniki, Greece, June 25-28.

Duval, A.M., Méneroud, J.P., Vidal, S.and Bard, P.Y. (1998). Relation between curves obtained from microtremor and site effects observed after Caracas 1967 earthquake, 11th European Conf. on Earthquake Engineering, Paris, France.

Frankel, A. and Vidale, J. 1992. A three-dimensional simulation of seismic waves in the Santa Clara valley, California, from a Loma Prieta aftershock, Bull. Seism. Soc. Am. 82, 2045-2074.

Groby J.P., Tsogka C., Wirgin A. (2005). Simulation of seismic response in a city-like environment, Soil Dynamics and Earthquake Eng. 25, no.7-10, 487-504.

Guéguen P., Bard P.Y., Oliveira C.S. (2000). Experimental and numerical analysis of soil motions caused by free vibrations of a building model, Bull. Seism. Soc. Am. 90, no.6, 1464-1479.

Humbert P., Dubouchet A., Feyzans G., Remaud D. (2005). CESAR-LCPC: A computation software package dedicated to civil engineering uses, Bulletin des Laboratoires des Ponts et Chaussées, 256-257, 7-37.

Jennings P.C. (1970). Distant motions from a building vibration test, Bull. Seism. Soc. Am. 60, pp.2037-2043.

Kham M., Semblat J-F., Bard P-Y., Dangla P. (2006). Seismic site-city interaction: main governing phenomena through simplified numerical models, Bull. Seism. Soc. Am. 96, no.5, 1934-1951.

Lombaert G., Clouteau D., Ishizawa O., Mezher N. (2004). The city-site effect: a fuzzy substructure approach and numerical simulations, 11th Int. Conf. on Soil Dynamics and Earthquake Eng., Berkeley.

Mezher N. (2004). Numerical Modelling and quantification of the site-city seismic effect (In French), $\mathrm{PhD}$ Thesis École Centrale Paris, France.

Niu Y and Dravinski M. (2003). Direct 3D BEM for scattering of elastic waves in a homogenous anisotropic half-space, Wave Motion, 38, 165-175.

Paolucci, R. (1999). Shear resonance frequencies of alluvial valleys by Rayleigh's method, Earthquake Spectra, 15, 503-521.

Paolucci, R. (2002). Amplification of earthquake ground motion by steep topographic irregularities, Earthquake Eng. And Structural Dynamics, 31, 1831-1853.

Pitilakis, K.D., Raptakis, D.G., Makra, K.A. (1999). Site effects : recent considerations and design provisions, 2nd Int. Conf. on Earthquake Geotechnical Eng., Lisbon, Balkema ed, 901-912.

Sánchez-Sesma F.J. and F. Luzon (1995). Seismic response of three-dimensional alluvial valleys for incident P, S and Rayleigh waves, Bull. Seism. Soc. Am. 85, 269-284.

Semblat, J.F., Duval, A.M., Dangla P. (2000). Numerical analysis of seismic wave amplification in Nice (France) and comparisons with experiments, Soil Dynamics and Earthquake Eng. 19, no.5, 347-362.

Semblat, J.F., Duval, A.M., Dangla P. (2002). Seismic site effects in a deep alluvial basin: numerical analysis by the boundary element method, Computers and Geotechnics, 29, no.7, 573-585. 
Semblat J.F., Paolucci R., Duval A.M. (2003). Simplified vibratory characterization of alluvial basins, C.R. Geosciences, 335, no.4, 365-370.

Semblat J.F., Kham M., Parara E., Bard P.Y., Pitilakis K., Makra K., Raptakis D. (2005). Site effects : basin geometry vs soil layering, Soil Dynamics and Earthquake Eng. 25, no.7-10, 529-538.

Trifunac, M.D., and Brady, A.G. (1975). A study on the duration of strong earthquake ground motion, Bull. Seism. Soc. Am. 65, no.3, 581-626.

Wirgin A., and Bard, P-Y. (1996). Effects of buildings on the duration and amplitude of ground motion in Mexico city, Bull. Seism. Soc. Am. 86, 914-920. 


\section{Figure captions:}

Figure 1. 2D alluvial basin considered in Nice (middle) ; 1D and 2D computed spectral amplification factors vs site/reference spectral ratio (bottom) and time domain response for the Feb.2001 earthquake (top).

Figure 2. The site-city models (regular, irregular) involving an alluvial basin.

Figure 3. Transfer functions of the ground motion along the basin for the different city models (regular $(\mathrm{N}=33)$, irregular and realistic) and comparison with the free-field results.

Figure 4. Ground motion time histories (normalized displacement) along the basin for the different city models (regular $(\mathrm{N}=33)$, irregular and realistic) for a Ricker wavelet with $0.8 \mathrm{~Hz}$ central frequency. Comparison with the free-field results.

Figure 5. Ground motion duration along the basin surface for the B1S (left) and B2S (right) city models (various building densities) excited by Ricker wavelets with central frequencies $\mathrm{f}^{\mathrm{R}}=0.8 \mathrm{~Hz}$ (top) and $\mathrm{f}^{\mathrm{R}}=2 \mathrm{~Hz}$ (bottom).

Figure 6. Free-field (top), urban ground motion (middle) and perturbations (bottom) induced by the B1S city $(\mathrm{N}=33)$ for $\mathrm{f}^{\mathrm{R}}=0.8 \mathrm{~Hz}$.

Figure 7. Urban ground motion (top) and perturbations (bottom) induced by the B2S city $(\mathrm{N}=33)$ for $\mathrm{f}^{\mathrm{R}}=0.8 \mathrm{~Hz}$.

Figure 8. Ground motion energy along the basin for the various B1S and B2S cities under a Ricker wavelet $\left(\mathrm{f}^{\mathrm{R}}=0.8 \mathrm{~Hz}\right.$ and $\left.2 \mathrm{~Hz}\right)$ and the Feb.2001 earthquake: total ground motion (thick lines), perturbations (thin lines).

Figure 9. Urban ground motion (top) and perturbations (bottom) induced by the irregular city for $\mathrm{f}^{\mathrm{R}}=0.8 \mathrm{~Hz}$.

Figure 10. Ground motion energy along the basin for the irregular city under a Ricker wavelet $\left(\mathrm{f}^{\mathrm{R}}=0.8 \mathrm{~Hz}\right.$ and $\left.2 \mathrm{~Hz}\right)$ and the Nice 2001 earthquake.

Figure 11. Description of the realistic city model.

Figure 12. Urban ground motion (top) and perturbations (bottom) induced by the realistic city under a Ricker wavelet $\left(\mathrm{f}^{\mathrm{R}}=0.8 \mathrm{~Hz}\right)$.

Figure 13. Ground motion energy (top) and perturbation energy (bottom) along the basin for the realistic city under a Ricker wavelet $\left(\mathrm{f}^{\mathrm{R}}=0.8 \mathrm{~Hz}\right.$ and $\left.2 \mathrm{~Hz}\right)$ and the Feb.2001 earthquake.

Figure 14. Comparison of the free-field motion and the surface displacement induced by the Feb.2001 earthquake for three different locations and various city configurations. 

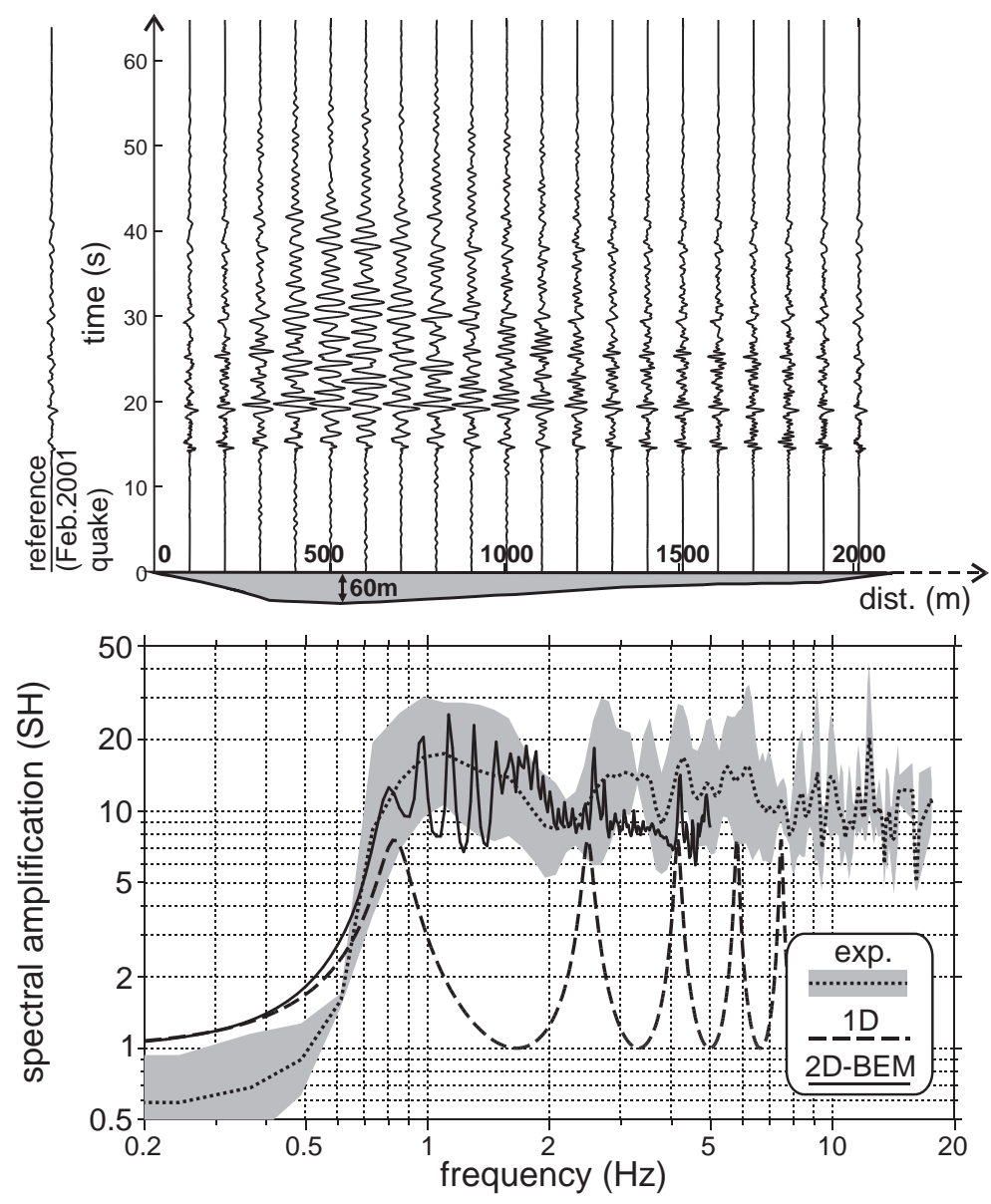

Figure 1 
Irregular city model

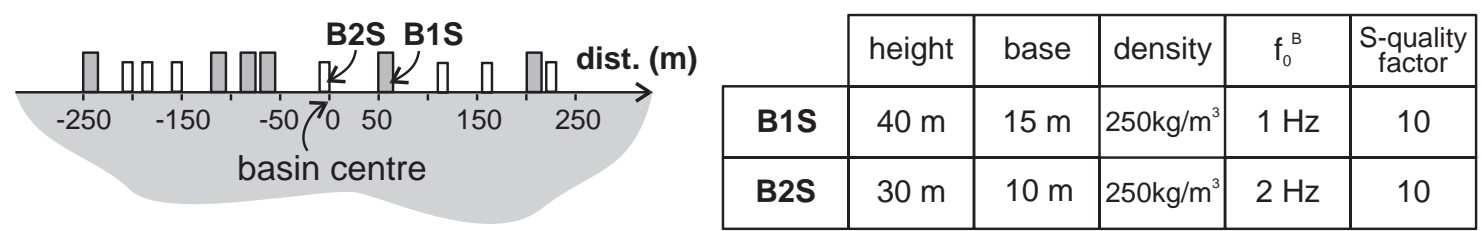

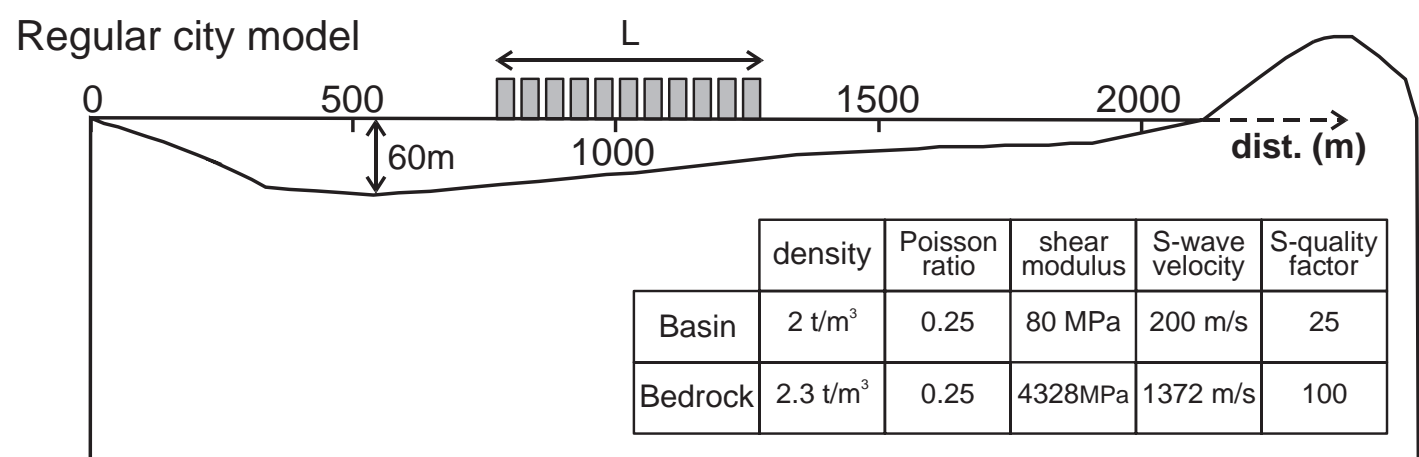

Figure 2 

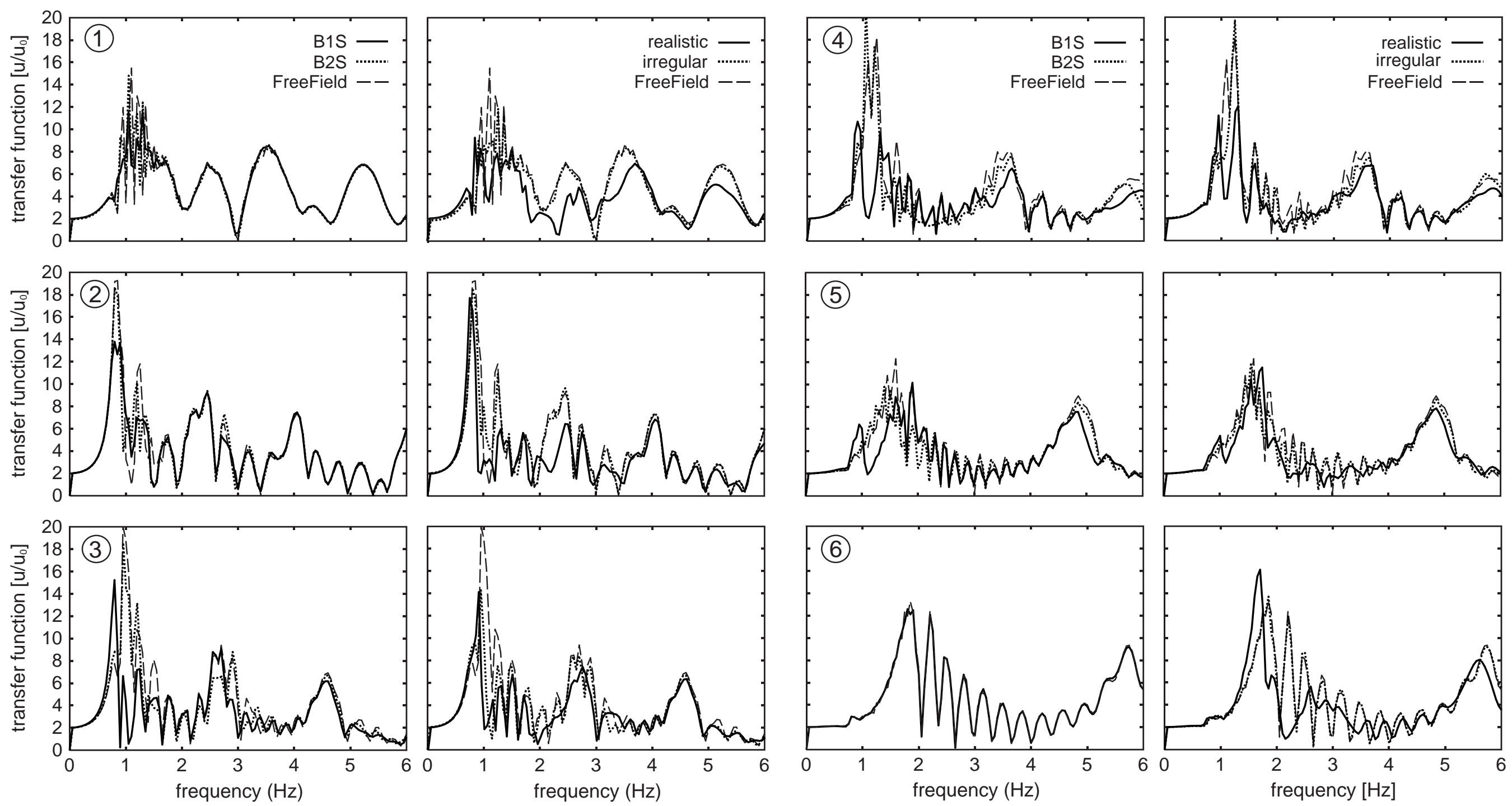

Figure 3 

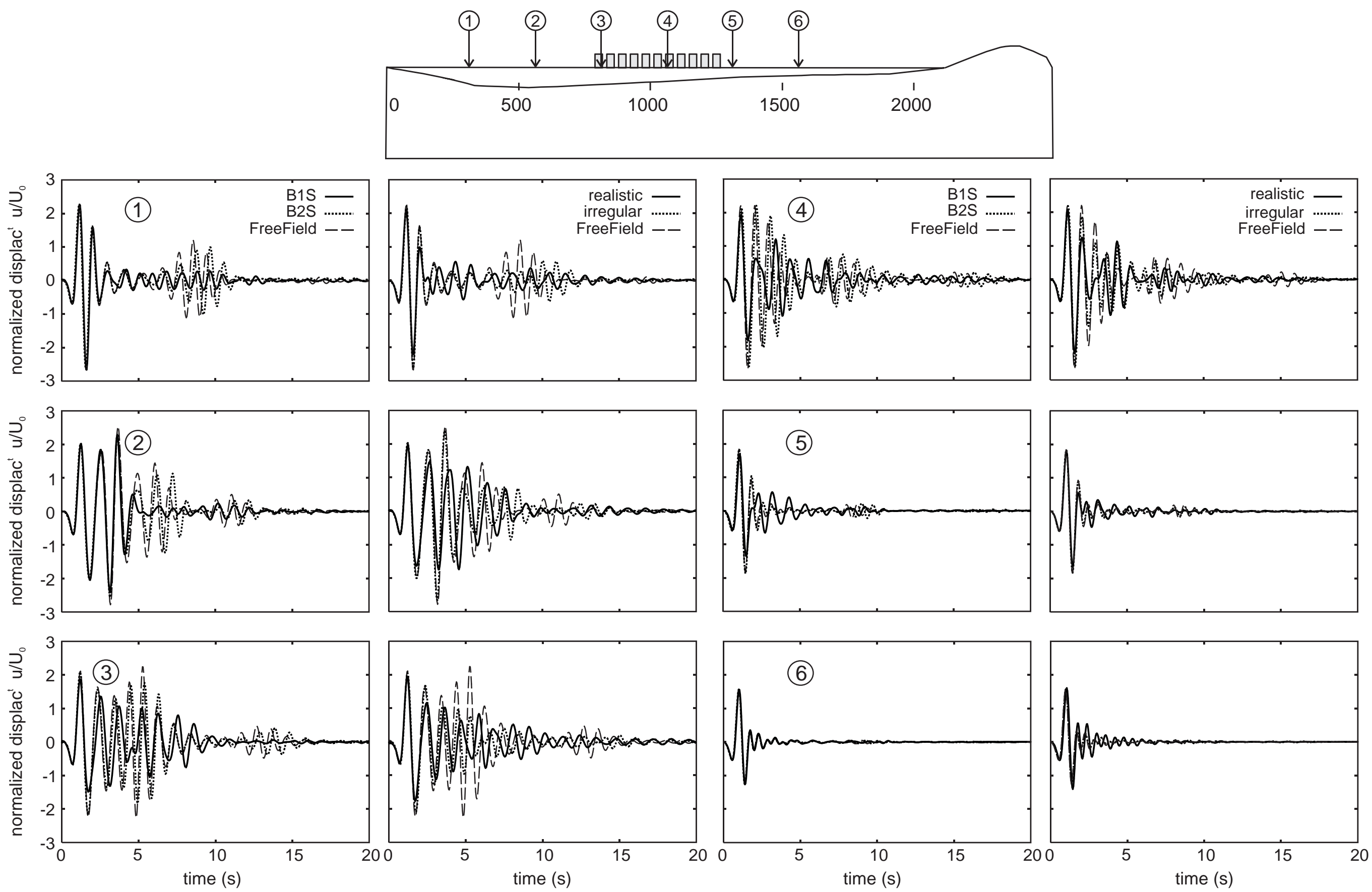

Figure 4 

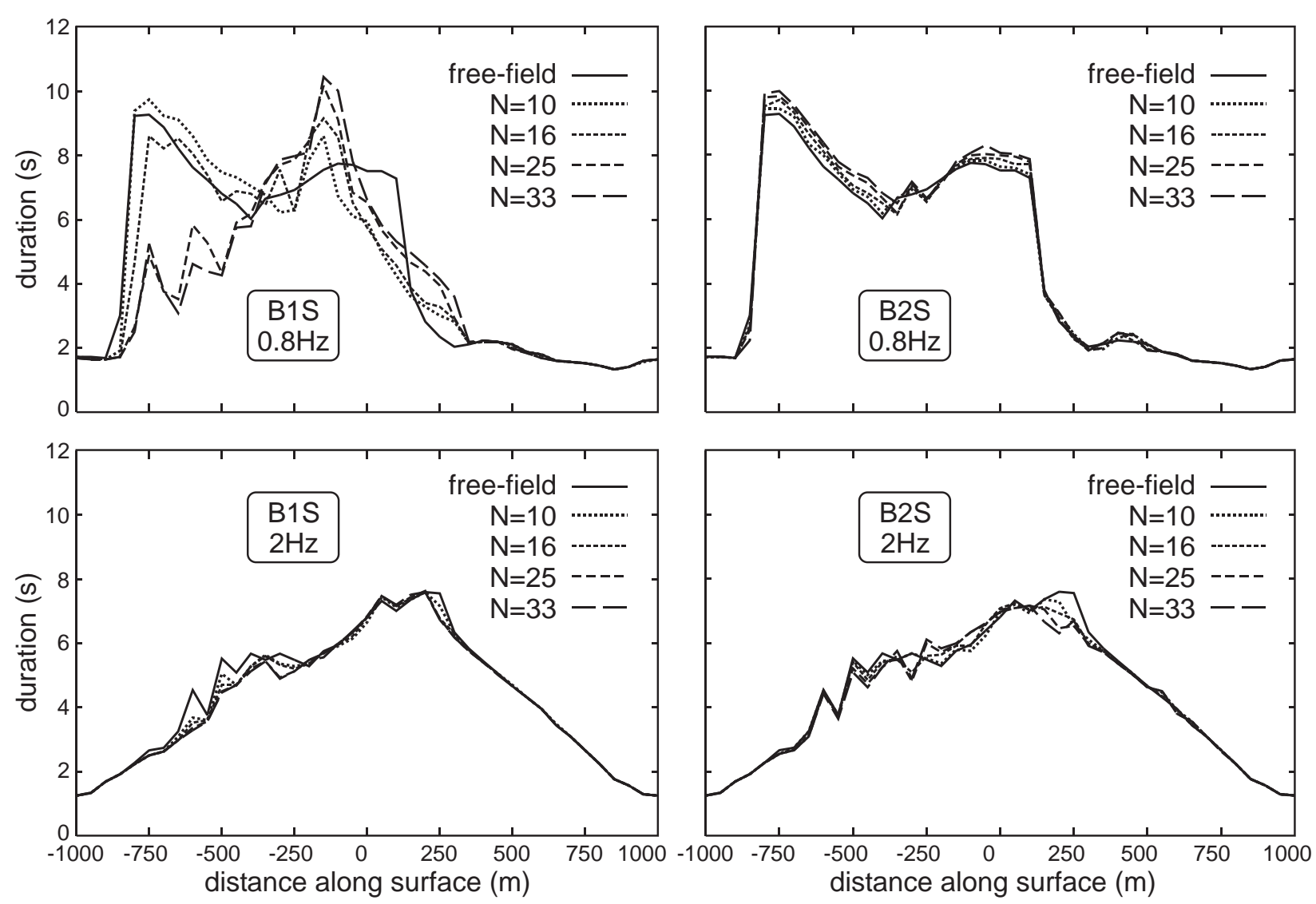

Figure 5 

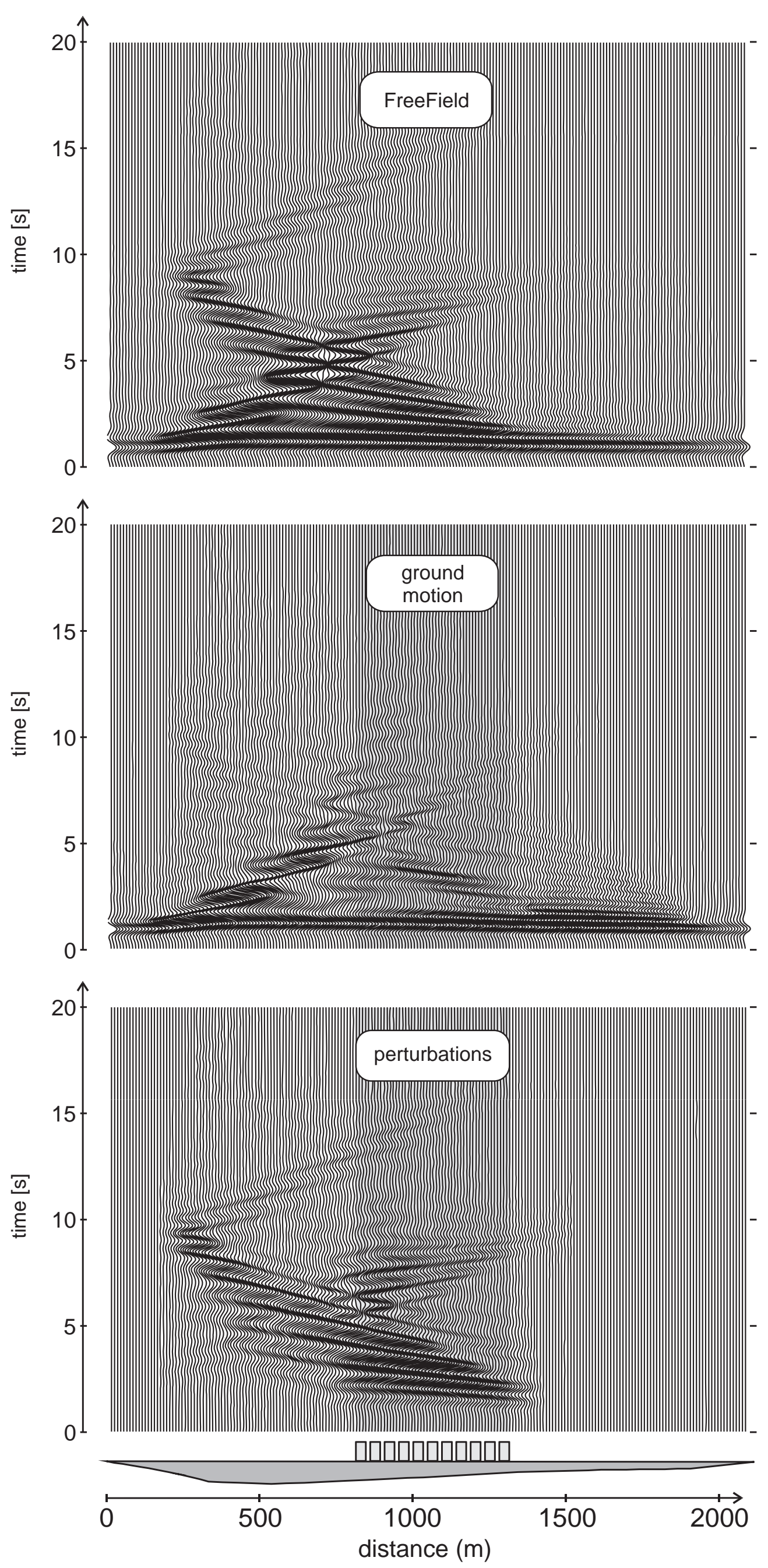

Figure 6 

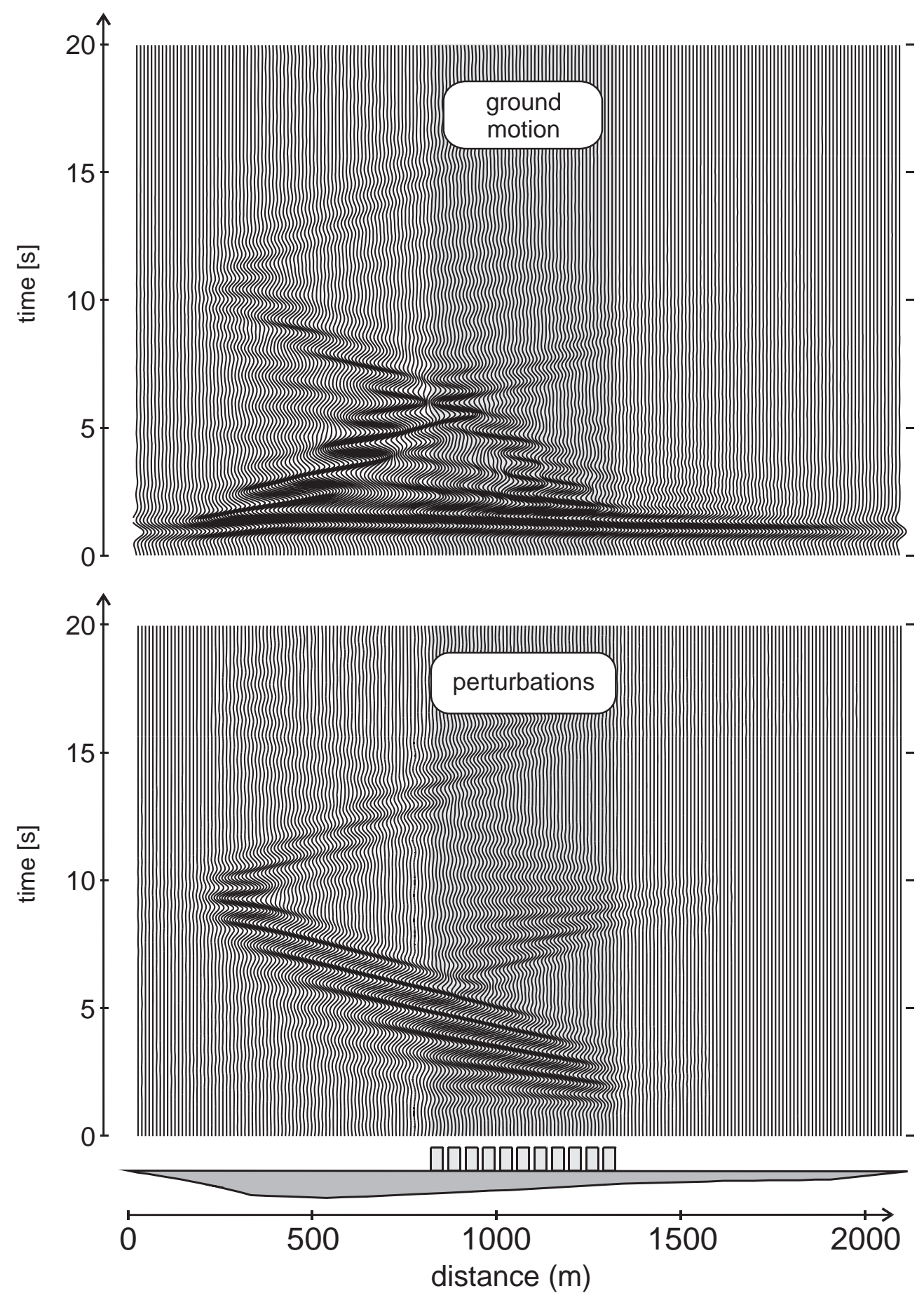

Figure 7 


\section{B1S}
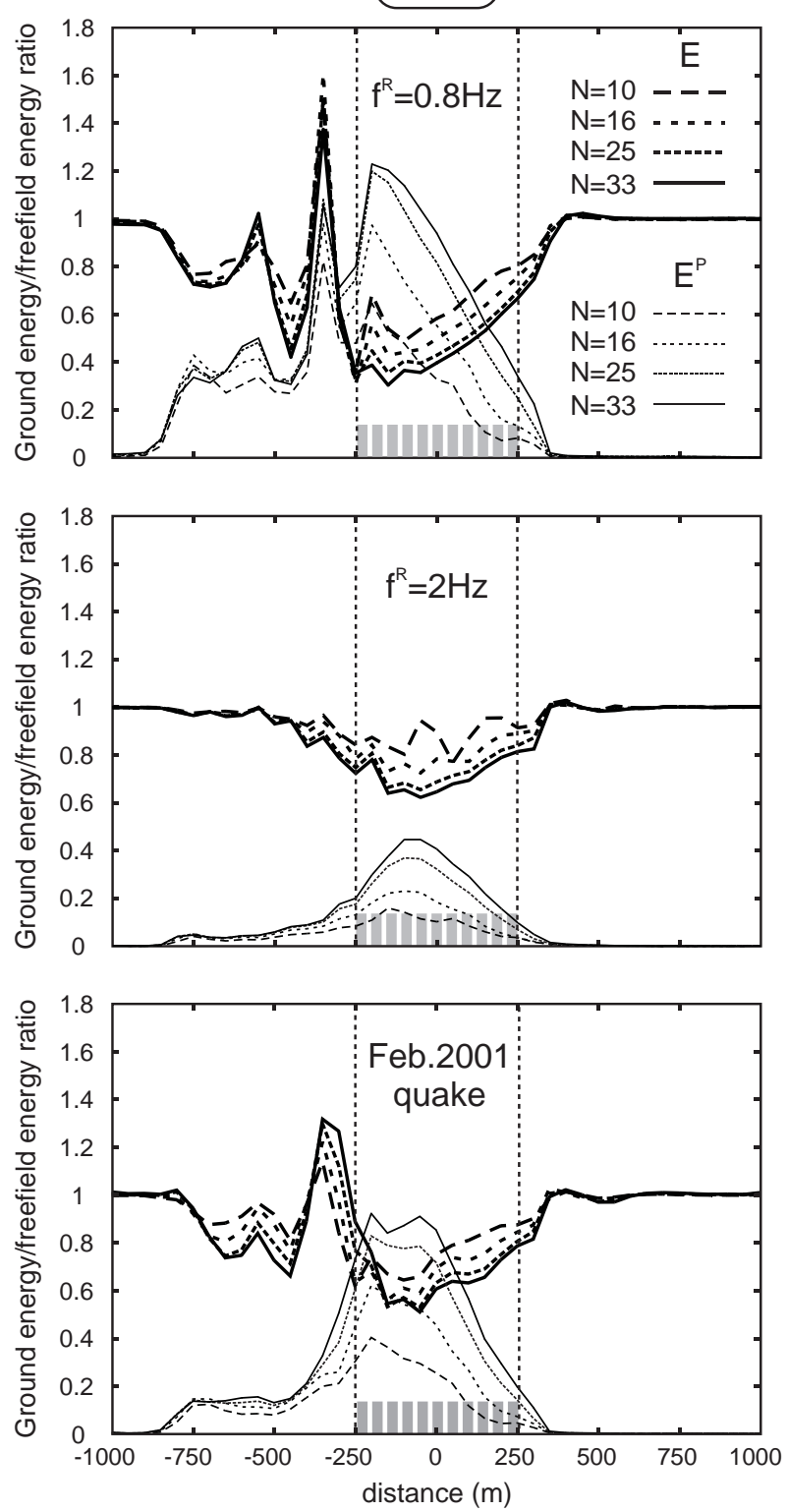

B2S
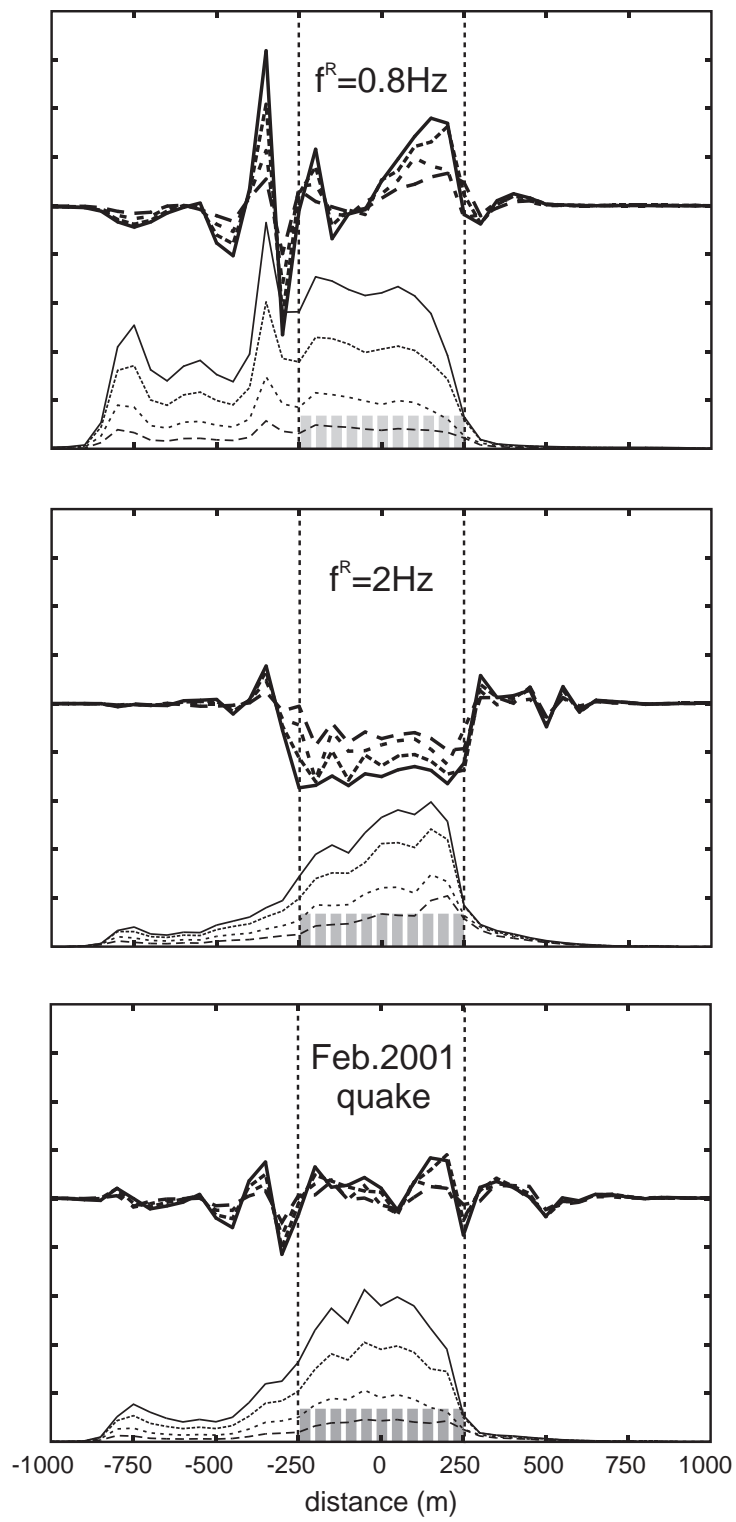

Figure 8 

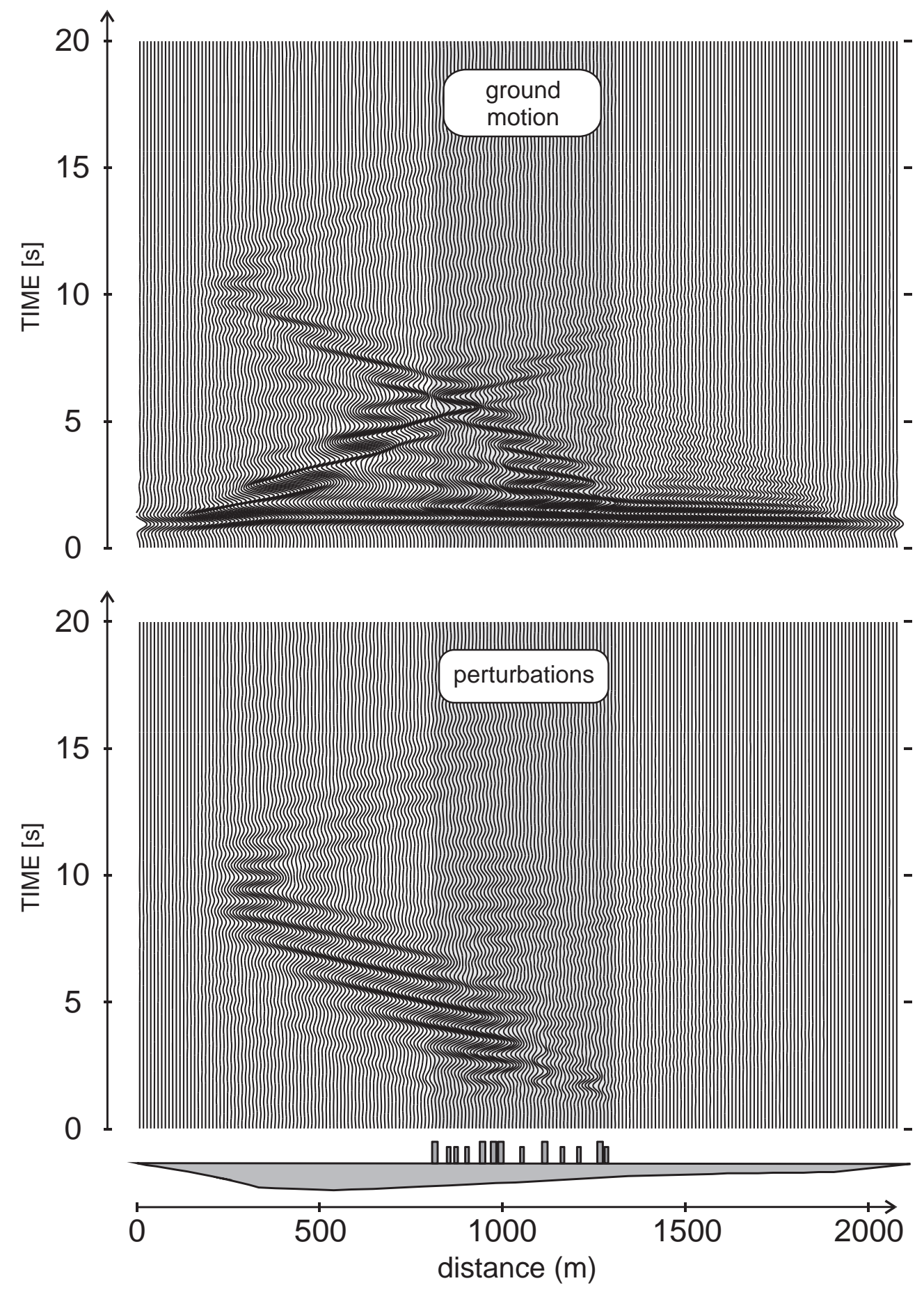

Figure 9 


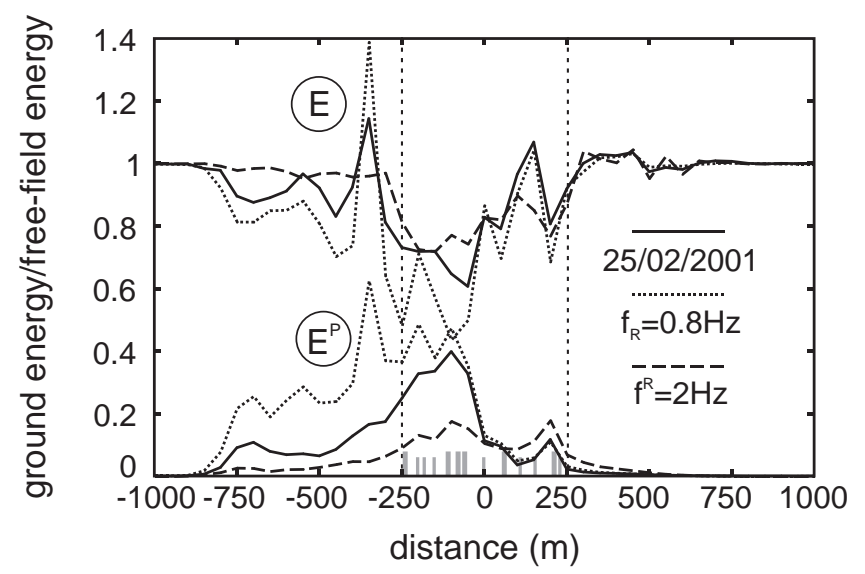

Figure 10 


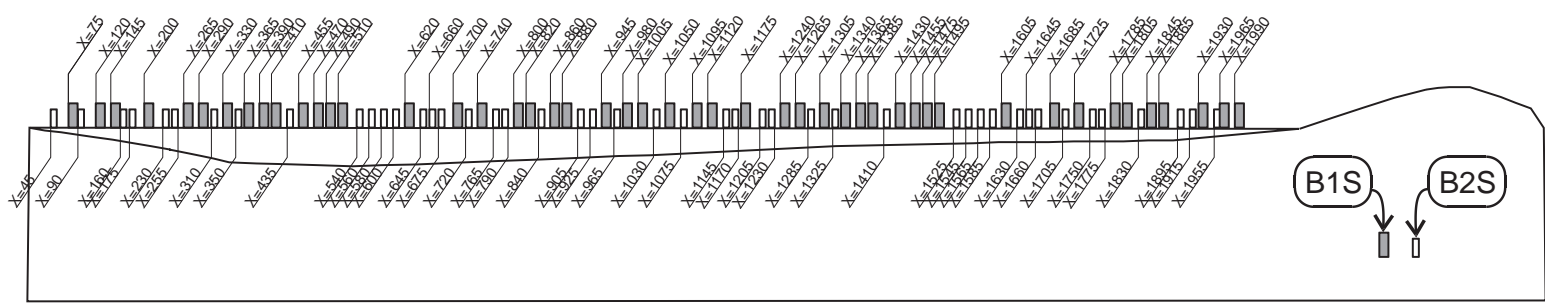

Figure 11 

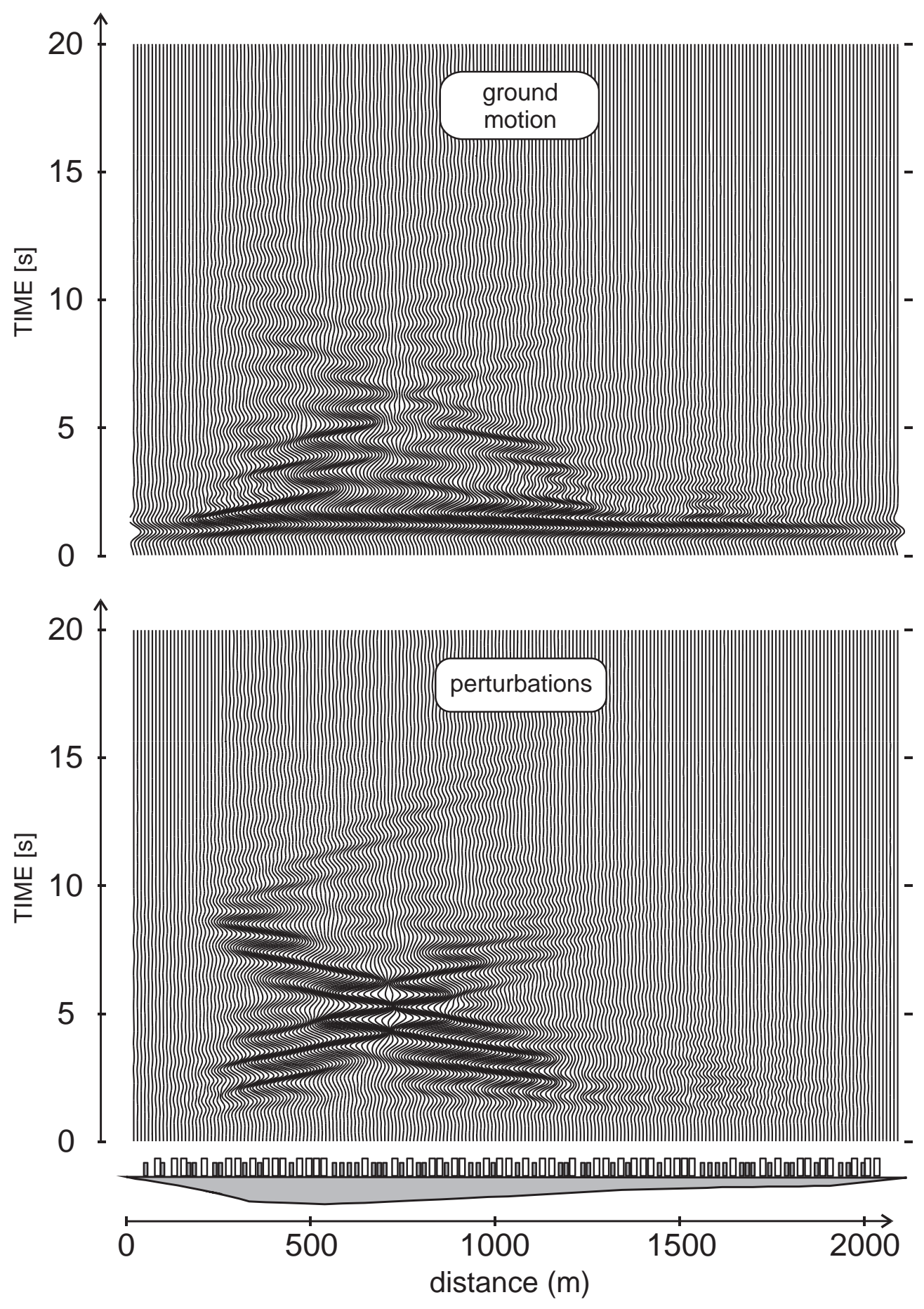

Figure 12 

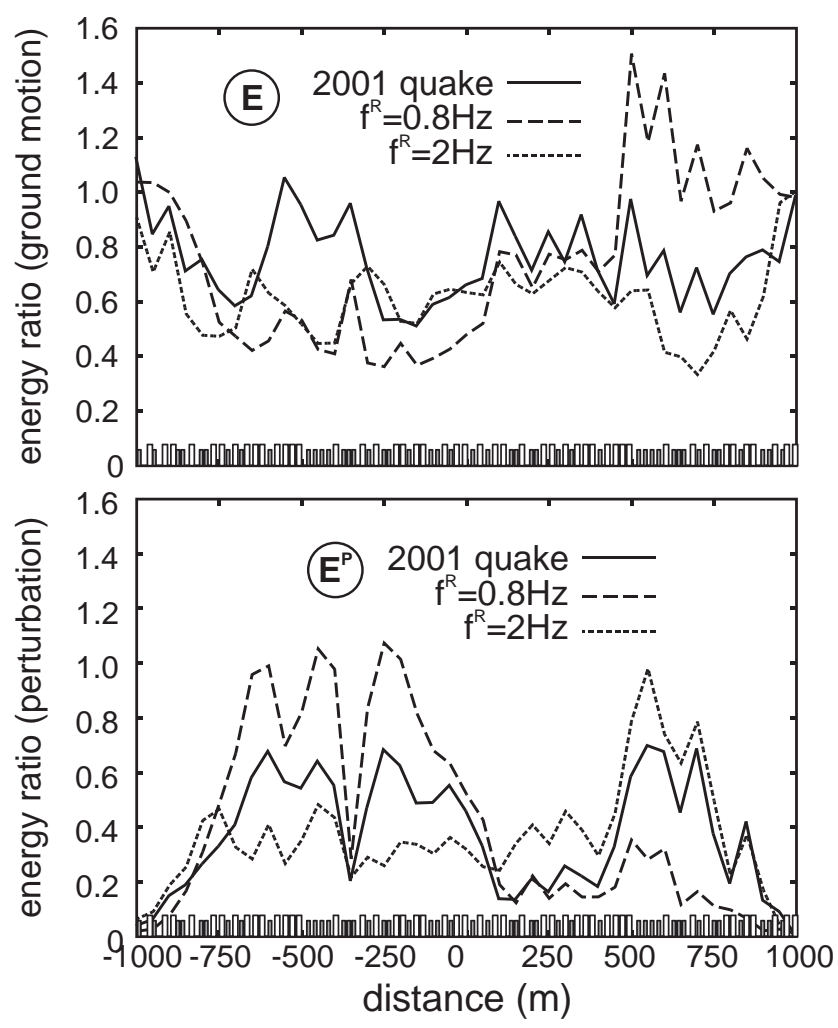

Figure 13 

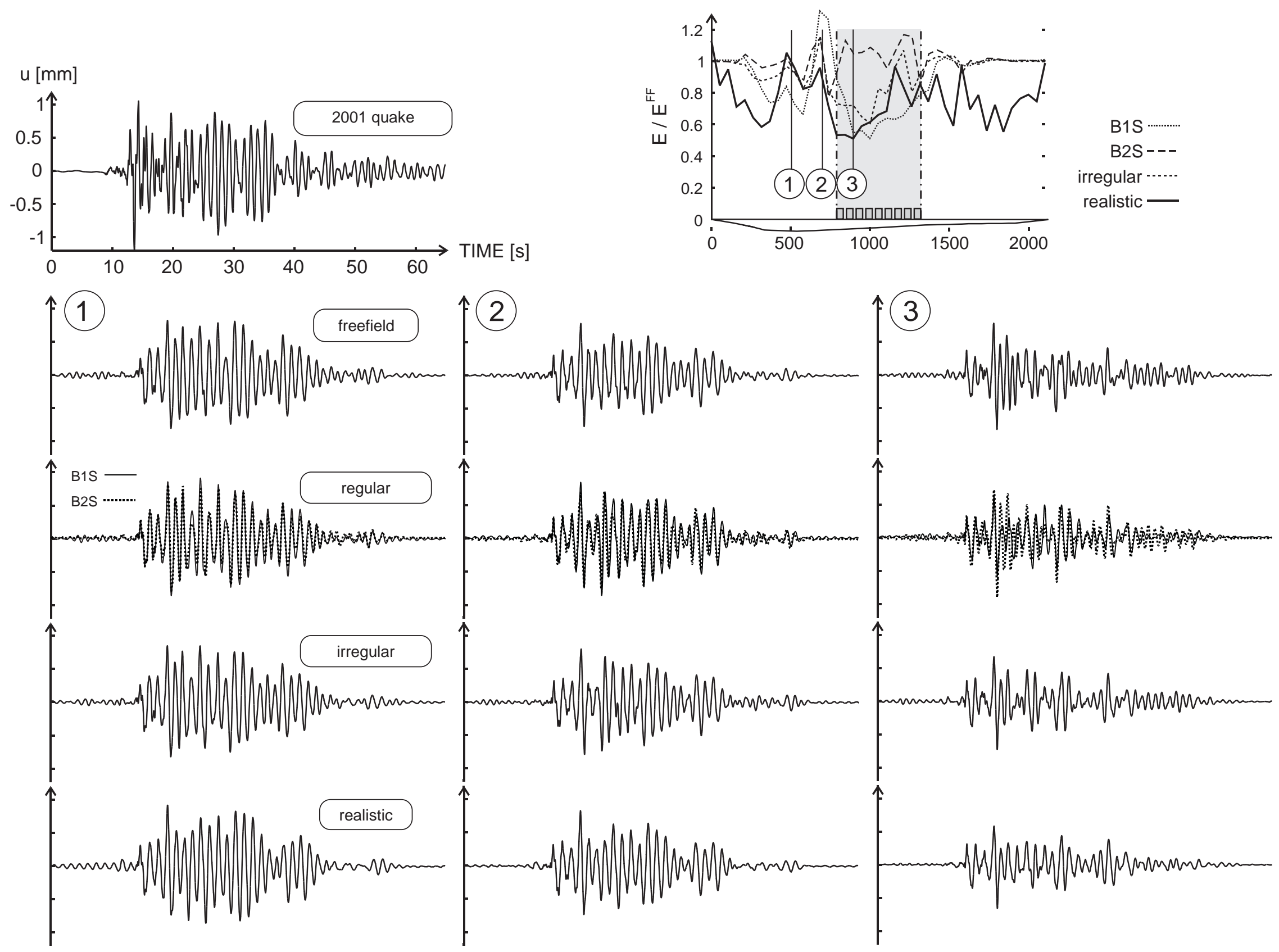

Figure 14 